\title{
PENGGUNAAN PROGRAM KOMPUTER PADA GEDUNG BERTINGKAT MENGGUNAKAN PAKET PROGRAM SANSPRO V 4,7
}

\author{
Oleh: Singgih Subagyo ${ }^{1}$ \\ E-mail: singgihsubagyohadi@gmail.com
}

\begin{abstract}
ABSTRAK: Berada di daerah gempa yang aktif, semua bangunan di Indonesia harus direncanakan mengikuti persyaratan yang ketat dari peraturan bangunan sehingga mampu menahan beban gempa yang direncanakan, khususnya dengan menggunakan peraturan bangunan dan peraturan gempa yang baru. SANSPRO, suatu program terpadu untuk Pemodelan, Analisis, Desain, Penggambaran, dan Perhitungan Biaya Struktur, dapat menjadi suatu alat bantu yang sangat berguna untuk meningkatkan mutu desain di Indonesia. Program ini dapat digunakan sebagai alat bantu belajar, dan juga sebagai alat desain sehari-hari.
\end{abstract}

Perencanaan struktur dengan konsep kapasitas menuntut proses yang cukup rumit dibandingkan dengan perencanaan tanpa konsep kapasitas. Penelitian ini ingin memeriksa perilaku struktur rangka beton bertulang yang direncanakan tanpa konsep kapasitas (cara biasa) serta membandingkan kemampuan struktur tersebut dengan struktur yang direncanakan dengan konsep kapasitas. Model bangunan yang dipakai adalah struktur rangka beton bertulang bertingkat 6 yang terletak di wilyah gempa 2 Indonesia, memiliki bentuk dan ukuran denah yang sama.

Struktur tersebut dibebani dengan gempa El Centro 1940 M-Sedang. Akibat gempa El Centro $1940 N-S$, hampir semua model struktur masih bersifat elastis. Hal ini terjadi karena gempaEl Centro 1940N-S termasuk gempa kecil sampai sedang di wilayah gempa 2 Indonesia. Dari pembebanan gempa 200 tahun tertihat bahwa model struktur yang direncanakan dengan Cara Kapasitas memberikan hasil yang memuaskan. Mekanisme terjadinya sendi plastis sesuai dengan yang diinginkan. Daktilitas balok maupun kolom yang tersedia cukup untuk memencarkan energi gempa.

Kata-kata Kunci : daktail, desain kapasaitas, gempa.

\section{PENDAHULUAN}

\subsection{Latar Belakang}

Indonesia sebagai negara kepulauan adalah kumpulan gugusan pulau yang secara geografis terletak antara $6^{\circ} \mathrm{LU}-11^{\circ} \mathrm{LS}$ dan $95^{\circ} \mathrm{BT}-140^{\circ} \mathrm{BT}$. Indonesia merupakan daerah pertemuan antara tiga lempeng dunia yang aktif yaitu lempeng Eurasia, Pasifik dan Hindia-Australia yang menjadikan kepulauan Indonesia rawan terhadap terjadinya patahan yang dapat menyebabkan gempa bumi tektonik

Gempa bumi didefinisikan sebagai gerakan tiba-tiba atau rentetan gerakan tiba-tiba dari tanah dan batuan yang bersifat transient atau sementara dan berasal dari suatu daerah terbatas yang kemudian menyebar ke segala arah karena dirambatkan oleh medium yang ada (lapisan bumi) (Cholid mahmud: Diktat analisis gempa).

Parameter gempa adalah acuan nilai besaran dan letak kejadian suatu gempa. besaran gempa merupakan suatu ukuran kekuatan yang dihitung berdasarkan data dari alat perekam gempa atau seismograf. Selain itu, parameter gempa harus mampu mempresentasikan letak pusat gempa. Parameter gempa yang memprsentasikan lokasi pusat gempa (hypocenter) dan episentrum (Epicenter).

1) adalah staf pengajar Program Studi Teknik Sipil Universitas Cokroaminoto Yogyakarta 
Hiposentrum adalah "titik" dimana energi elastic dilepaskan dalam bentuk gelombang gempa sehingga menimbulkan getaran pada bola bumi. Dengan kata lain, hiposentrum adalah lokasi dari pusat terjadinya gempa (Cholid Mahmud: Diktat analisis gempa) Perencanaan struktur gedung bertingkat tinggi membutuhkan perencanaan yang sangat cermat dan teliti. Hal ini dimaksudkan untuk memperoleh struktur bangunan yang mampu menahan terhadap gaya - gaya lateral baik gaya gempa, gaya angin atau kombinasi dari keduanya. Selain itu pengaruh akibat gravitasi juga harus diperhatikan sehingga struktur tidak mengalami kerusakan yang fatal sehingga menyebabkan runtuhnya bangunan.

Kenyataannya bahwa perilaku keruntuhan bangunan saat gempa adalah inelastis. Evaluasi yang dapat memperkirakan kondisi inelastis bangunan saat gempa perlu untuk mendapatkan jaminan bahwa kinerjanya memuaskan saat gempa terjadi.

\subsection{Rumusan Masalah}

Berdasarkan uraian yang telah dijelaskan diatas, maka permasalahan yang timbul dalam permasalahan tugas akhir ini, yaitu sudah amankah struktur yang menahan beban-beban yang bekerja pada struktur dan termasuk beban gempa dengan mempertimbangkan segi kekakuan, kekuatan, keamanan, serta segi ekonomis dari struktur tersebut.

Tinjauan yang akan dilakukan adalah perencanaan elemen struktur(balok, pelat dan kolom) yang aman mendukung struktur terhadap variasi pembebanan akibat beben mati, beban hidup, beban gempa, dan akibat kombinasi pembebanan.

\subsection{Batasan Masalah}

Dalam perhitungan ini digunakan batasan - batasan sebagai berikut:

1. Analisis ini membahas struktur dari bawah sampai struktur atas, yang meliputi, balok, kolom dan pelat lantai pada bangunan.

2. Pembebanan yang ada terdiri dari beban mati, beban hidup dan beban gempa.

3. Perencanaan pembebanan gedung sesuai dangan Peraturan Pembebanan Indonesia untuk gedung 1983, dan perhitungan beban dan kombinasinya sesuai dengan SK - SNI T - 15-1991- 03.

4. Analisis struktur dilakukan dengan bantuan Komputer menggunakan software SANSPRO full version.

5. Analisa dalam tugas akhir ini struktur yang di gunakan adalah beton bertulang.

\subsection{Tujuan}

Tujuan dan penulisan penelitian ini adalah untuk :

1. Menganalisa portal gedung bertingkat dengan program SANSPRO

2. Mengetahui karakteristik bangunan pada daerah rawan gempa meskipun dalam tugas akhir ini study yang digunakan adalah wilayah gempa II yang merupakan wilayah gempa sedang, tapi dalam perencanaannya tetap harus memperhatikan kemungkinan gempa yang terjadi.

3. Lebih memahami keuntungan dengan menggunakan program SANSPRO sistem kerja dari program SANSPRO

\subsection{Manfaat}

Beragamnya software perhitungan struktur yang beredar dapat meningkatkan skill seorang engineer. Dengan skill yang berkualitas dari seorang engineer akan semakin meningkatkan keamanan pada pelaksanaan konstruksi tahan gempa khususnya pada daerah rawan gempa Selain itu juga untuk mendapatkan pengalaman dan memahami merancang gedung bertingkat dan komplek sehingga dalam dunia kerja nantinya dapat diaplikasikan sesuai dengan yang telah dipelajari. 
Beberapa keuntungan yang didapat dari penggunaan software SANSPRO adalah hasil penulangan lentur bisa langsung di dapat hanya dengan memberikan data kuat lentur dan diameter tulangan, gambar tulangan bisa langsung ditampilkan, gambar potongan memanjang dan melintang (SANSPRO full version) dan masih banyak yang lain.sehingga mempermudah perencanaan dan pelaksanaan.

\subsection{Keaslian}

Penelitian semacam ini sebenarnya kelanjutan dari beberapa penelitian yang pernah di lakukan oleh teman - teman dari mahasiswa dari Jurusan Tekink Sipil hanya saja penelitian yang lain menggunakan program SAP 2000,ETAB, STAAD PRO dan software - software yang lain. Sedangkan dalam tugas akhir ini peneliti mencoba melakukan penelitian dengan menggunakan Program SANSPRO yang merupakan salah satu produk dalam negeri dari enginering sotware research center (ESRC) yang dipimpin oleh Ir. Nathan Madutujuh, M.Sc.

\section{TINJAUAN PUSTAKA}

\subsection{Umum}

\section{A. Program Sanspro Sebagai Alat Bantu Perencanaan Struktur}

Program komputer analisis dan desain struktur (SANSPRO) pada awalnya (1988) dirancang dengan filosofi lama dimana software masih dianggap sebagai alat bantu analisis saja, sebagai berikut: Perencana memanfaatkan komputer sebagai alat bantu analisis dan desain struktur. Sedangkan penggambaran akhir dan perhitungan volume dilakukan dengan kontrol ketat manusia

\section{B. Analisis Beban Dorong Statik}

Adalah suatu analisis statik nonlinier di mana pengaruh Gempa Rencana terhadap struktur bangunan gedung dianggap sebagai beban-beban statik yang menangkap pada pusat massa masing-masing lantai yang sering disebut pushover analysis

\section{Properti Sendi}

Pemodelan sendi digunakan untuk mendefinisikan perilaku nonlinier forcedisplacement dan atau momen-rotasi yang dapat ditempatkan pada beberapa tempat berbeda di sepanjang bentang balok atau kolom. Pemodelan sendi adalah rigid dan tidak memiliki efek pada perilaku linier pada member. Dalam studi ini, elemen kolom menggunakan tipe sendi default- $P M M$, dengan pertimbangan bahwa elemen kolom terdapat hubungan gaya aksial dengan momen (diagram interaksi PM).

\section{Metode Displacement Coefficient FEMA 356}

Pada metode displacement coefficient (FEMA 356), perhitungan dilakukan dengan memodifikasi respons elastik linier sistem struktur SDOF ekivalen dengan faktor modifikasi $\mathrm{CO}, \mathrm{C1}, \mathrm{C2}$ dan $\mathrm{C3}$ sehingga dapat dihitung target peralihannya, dengan menetapkan dahulu waktu getar efektif $(T e)$ untuk memperhitungkan kondisi inelastic struktur gedung.

$$
\delta_{t}=C_{0} \cdot C_{1} \cdot C_{2} \cdot C_{3} \cdot S_{a} \cdot\left(\frac{T_{e}}{2 \cdot \pi}\right)^{2} \cdot g
$$

\section{Dimana :}

- $\delta t$ target peralihan.

- Te waktu getar alami efektif.

60 Penggunaan Program Komputer Pada Gedung Bertingkat Menggunakan Paket Program Sanspro V 4,7 (Singgih Subagyo) 
- CO faktor modifikasi untuk mengkonversi spectral displacement struktur SDOF ekivalen menjadi roof displacement struktur sistem MDOF, sesuai FEMA 356 Tabel 3-2.

- $\quad$ C1 faktor modifikasi untuk menghubungkan peralihan inelastik maksimum dengan peralihan respons elastik linier. Nilai $C 1=1,0$ untuk $T e \geq T s$ dan

$$
C_{l}=\frac{\left[1+(R-1) \cdot \frac{T_{s}}{T_{e}}\right]}{R} \text { untuk } T_{e}<T_{s} \text {. }
$$

- C2 faktor modifikasi untuk memperlihatkan pinched hysteresis shape, degradasi kekakuan dan penurunan kekuatan pada respon peralihan maksimum, sesuai FEMA 356 tabel 3-3.

- C3 faktor modifikasi untuk memperlihatkan kenaikan peralihan akibat efek p-delta. Untuk gedung dengan perilaku kekakuan pasca-leleh bernilai positif maka C3 $=1,0$. Sedangkan untuk gedung dengan perilaku kekakuan pasca-leleh negatif,

$$
C_{3}=1,0+\frac{|\alpha|(R-1)^{3 / 2}}{T_{e}}
$$

- $R$ adalah strength ratio, besarnya dapat dihitung dengan persamaan

$$
R=\frac{S_{a}}{V_{y} / W} \cdot C_{m}
$$

- Sa adalah akselerasi spektrum respons pada waktu getar alami fundamental efektif dan rasio redaman pada arag yang ditinjau.

- $V y$ adalah gaya geser dasar pada saat leleh.

- Wadalah berat efektif seismic.

- Cm faktor massa efektif, tabel 3-1 FEMA 356 3-1.

- $\alpha$ adalah rasio kekakuan pasca leleh dengan kekakuan elastik efektif, dimana hubungan gaya peralihan nonlinier diidealisasikan sebagai kurva bilinier (lihat gambar).

- Ts waktu getar karakteristik respons spektrum.

- $g$ percepatan gravitasi $9,81 \mathrm{~m} / \mathrm{det}^{2}$.

\section{E. Metode Displacement Coefficient FEMA 440}

Merupakan metode displacement coefficient pada FEMA 356 yang telah dimodifikasi dan diperbaiki. Persamaan yang digunakan untuk menghitung target peralihan tetap sama, yaitu sesuai persamaan (5). Akan tetapi mengalami modifikasi dan perbaikan dalam menghitung faktor $C 1$ dan $C 2$ sebagai berikut :

$$
C_{1}=1+\frac{R-1}{a \cdot T_{e}^{2}}
$$

Nilai konstanta a adalah 130, 90 dan 60 untuk site kategori B, C dan D. Untuk waktu getar $<0,2$ detik maka nilai $C 1$ pada 0,2 detik dapat dipakai, sedangkan untuk waktu getar $>1$ detik maka $C 1=1,0$.

$$
C_{2}=1+\frac{1}{800}\left(\frac{R-1}{T_{e}}\right)^{2}
$$

Untuk waktu getar $<0,2$ detik maka nilai $C 2$ pada 0,2 detik dapat dipakai, sedangkan untuk waktu getar $>0,7$ detik maka $C 2=1,0$ 


\section{F. Kinerja Batas Ultimit Menurut SNI 1726-2002}

Kinerja batas ultimit struktur gedung ditentukan oleh simpangan dan simpangan antar-tingkat maksimum struktur gedung akibat pengaruh Gempa Rencana dalam kondisi struktur gedung di ambang keruntuhan, yaitu untuk membatasi kemungkinan terjadinya keruntuhan struktur gedung yang dapat menimbulkan korban jiwa manusia dan untuk mencegah benturan gedung yang dipisah dengan sela pemisah (sela delatasi). Simpangan dan simpangan antartingkat ini harus dihitung dari simpangan struktur gedung akibat pembebanan gempa nominal, dikalikan dengan suatu faktor pengali $\xi$ sebagai berikut :

a. Untuk struktur gedung beraturan :

$\xi=0,7 \cdot R$

b. Untuk struktur gedung tidak beraturan :

$$
\xi=\frac{0,7 \cdot R}{\text { Faktor Skala }}
$$

\section{G. Analisis Riwayat Waktu}

Beban gempa adalah fungsi waktu, sehingga respon pada struktur juga tergantung dari waktu pembebanan. Akibat Gempa Rencana struktur akan berperilaku inelastik. Untuk mendapatkan respon struktur tiap waktu dengan memperhitungkan perilaku nonlinier, maka dilakukan analisis riwayat waktu inelastic nonlinier dengan analisis langkah demi langkah (metode integrasi bertahap) memakai DRAIN-2D. Beban gempa yang digunakan adalah El Centro 1940, Bucharest 1977, Flores 1992 dan Pacoima Dam 1971.

\section{H. Massa}

Massa terpusat pada titik hubung elemen struktural. Massa secara proporsional dengan beban gravitasi adalah $W / g$, dengan nilai $\mathrm{g}=9,81 \mathrm{~m} / \mathrm{det}^{2}$. Karena gedung termasuk klasifikasi beraturan, maka digunakan model rigid diaphragm, yaitu massa dipusatkan pada satu titik nodal untuk tiap lantainya. Perhitungan presentase massa bangunan yang masuk pada rangka $2 \mathrm{D}$ sesuai dengan tributary area.

\section{Kurva Histeresis}

Kurva histeresis menyatakan respons riwayat waktu elemen struktur akibat beban dinamik, yang merupakan beban yang bersifat loading dan unloading. Model kurva histeresis pada program $D R A I N-2 D$ untuk elemen beton bertulang adalah model bilinier, memperhitungkan strain hardening setelah elemen struktur mengalami leleh. Pada penulisan ini, model histeresis menggunakan faktor bilinier $1 \%$.

\section{J. Redaman}

Model redaman program DRAIN-2D menggunakan redaman Rayleigh di mana matrik redaman struktur 46 Evaluasi Kinerja Gedung Beton Bertulang (Yosafat Aji Pranata) diperoleh dari persamaan cohəgai berikut :

$[\mathrm{C}]=\alpha \cdot[\mathrm{M}]+\beta \cdot[\mathrm{K}]$

$[\mathrm{C}]=$ matrik redaman struktur, $[\mathrm{M}]=$ matrı massa dan $[\mathrm{K}]=$ matrik kekakuan struktur. Koefisien $\alpha$ adalah koefisien redaman yang tergantung massa dan $\beta$ adalah koefisien redaman yang berhubungan dengan kekakuan, yang dihitung untuk memberikan tingkat yang dibutuhkan redaman viscous pada dua frekuensi yang berbeda, didapat dari nilai mode pertama dan mode kedua dari vibrasi bebas. 


\subsection{Konsep Desain Kapasitas}

Mekanisme goyang dengan pembentukan sebagian besar sendi plastis pada balok - balok lebih dikehendaki daripada mekanisme dengan pembentukan sendi plastis yang terpusat pada ujung - ujung kolom suatu lantai (soft-story mechanism). Guna menjamin terjadinya mekanisme goyang dengan pembentukan sebagian besar sendi plastis pada balok. Konsep Desain Kapasitas diterapkan untuk merencanakan agar kolom lebih kuat dari balok portal ( strong column weak beam ) (SNI-03-1726-2003).

\subsection{Beban Mati.}

Beban mati meliputi berat sendiri konstruksi dan semua unsur-unsur arsitektur seperti pelapis luar, sekat-sekat dan langit-langit.

\subsection{Beban Hidup}

Beban hidup adalah suatu beban yang bersifat tidak tetap dan ber ubah-ubah besarnya. Beban hidup yang digunakan dalam pembahasan ini berdasarkan PPI 1983 adalah beban hidup pada lantai gedung berdasar tabel 3.1. PPI 1983 adalah $250 \mathrm{~kg} / \mathrm{m}^{2}$.

\subsection{Beban Gempa}

Beban gempa adalah semua beban statik ekivalen yang bekerja pada gedung yang menirukan pengaruh dari pergerakan tanah akibat gempa tersebut. Dalam hal ini pengaruh gempa pada struktur gedung ditentukan berdasarkan analisa dinamik, yang diartikan sebagai beban gempa disini adalah gaya-gaya di dalam struktur tersebut yang terjadi oleh gerakan tanah akibat gempa tersebut (Cholid mahmud : diktat analisis gempa).

\section{LANDASAN TEORI}

\subsection{Umum}

Beton merupakan fungsi dari bahan penuyusunnya yang terdiri dari bahan semen hidrolik (Portland Cement),agregat kasar,agregat halus, air dan bahan tambah (admixture and additive).nawy(1985:8) mendefinisikan beton sebagai sekumpulan interaksi mekanis dan kimiawi dari material pembentuknya (Mulyono 2004)

Beton kuat terhadap tekan,tetapi lemah terhadap tarik.oleh karena itu, perlu tulangan untuk menahan gaya tarik untuk memikul beban-beban yang bekerja pada beton. Dalam tugas akhir ini struktur yang digunakan adalah beton bertulang.

\subsection{Kriteria Perencanaan}

Kriteria perencanaan dalam SKSNI T-15-1991-03 untuk perencanaan join balok dan kolom beton bertulang rangka terbuka:

1. Kekuatan join tidak boleh lebih kecil dari kekuatan komponen struktur yang di hubungkannya.

2. Karena kesulitan dalam perbaikannya dan penurunan kemampuan memancarkan energy pada mekanisme keruntuhan join maka seharusnya join tetap dalam keadaan elastis.

3. Kekuatn kolom tidak boleh di perlemah oleh karena perilaku join yang berdekatan dengannya.

4. Deformasi join tidak boleh memperbesar simpangan antar tingkat.

5. Pengaturan penulangan join tidak boleh mengakibatkan krumitan dalam perencanaan. 


\subsection{Beban Khusus}

Beban akibat selisih suhu, pengangkatan dan pemasangan, penurunan pondasi, susut, gaya rem dari keran, gaya sentrifugal, getaran mesin. Perencanaan komponen struktural gedung direncanakan dengan kekuatan batas (ULS), maka beban tersebut perlu dikalikan dengan faktor beban. Pada peninjauan beban kerja pada tanah dan pondasi, perhitungan Daya Dukung Tanah (DDT) izin dapat dinaikkan (PPIUG 1983).

\subsection{Beban Mati}

TABLE 3.1. BERAT SENDIRI BAHAN BANGUNAN KOMPONEN GEDUNG

\begin{tabular}{|l|r|c|}
\hline \multicolumn{1}{|c|}{ BAHAN BANGUNAN } & \multicolumn{1}{c|}{ BERAT } & SATUAN \\
\hline Baja & 7.850 & $\mathrm{Kg} / \mathrm{m}^{3}$ \\
\hline Batu alam & 2.600 & $\mathrm{Kg} / \mathrm{m}^{3}$ \\
\hline Batu Belah, batu bulat, batu gunung (berat tumpuk) & 1.500 & $\mathrm{Kg} / \mathrm{m}^{3}$ \\
\hline Batu karang (berat tumpuk) & 700 & $\mathrm{Kg} / \mathrm{m}^{3}$ \\
\hline Batu pecah & 1.450 & $\mathrm{Kg} / \mathrm{m}^{3}$ \\
\hline Besi tuang & 7.250 & $\mathrm{Kg} / \mathrm{m}^{3}$ \\
\hline Beton( ${ }^{1}$ ) & 2.200 & $\mathrm{Kg} / \mathrm{m}^{3}$ \\
\hline Beton bertulang( ${ }^{2}$ ) & 2.400 & $\mathrm{Kg} / \mathrm{m}^{3}$ \\
\hline Kayu (Kelas I)( ${ }^{3}$ ) & 1.000 & $\mathrm{Kg} / \mathrm{m}^{3}$ \\
\hline $\begin{array}{l}\text { Kerikil, koral(kering udara sampai lembab, tanpa } \\
\text { diayak) }\end{array}$ & 1.650 & $\mathrm{Kg} / \mathrm{m}^{3}$ \\
\hline Pasangan bata merah & 1.700 & $\mathrm{Kg} / \mathrm{m}^{3}$ \\
\hline Pasangan batu belah, batu belat, batu gunung & 2.200 & $\mathrm{Kg} / \mathrm{m}^{3}$ \\
\hline Pasangan batu cetak & 2.200 & $\mathrm{Kg} / \mathrm{m}^{3}$ \\
\hline Pasangan batu karang & 1.450 & $\mathrm{Kg} / \mathrm{m}^{3}$ \\
\hline Pasir (kering udara sampai lembab) & 1.600 & $\mathrm{Kg} / \mathrm{m}^{3}$ \\
\hline Pasir(jenuh air) & 1.800 & $\mathrm{Kg} / \mathrm{m}^{3}$ \\
\hline Pasir, kerikil, koral (kering udara sampai lembab) & 1.850 & $\mathrm{Kg} / \mathrm{m}^{3}$ \\
\hline $\begin{array}{l}\text { Tanah, lempung dan lanau (kering udara sampai } \\
\text { lembab) }\end{array}$ & 1.700 & $\mathrm{Kg} / \mathrm{m}^{3}$ \\
\hline Tanah, lempung dan lanau (basah) & 2.000 & $\mathrm{Kg} / \mathrm{m}^{3}$ \\
\hline Tanah hitam & 11.400 & $\mathrm{Kg} / \mathrm{m}^{3}$ \\
\hline
\end{tabular}

\subsection{Beban Hidup.}

Pada lantai gedung, sudah termasuk perlengkapan ruang sesuai dengan kegunaan dan juga dinding pemisah ringan $\left(q>100 \mathrm{~kg} / \mathrm{m}^{\prime}\right)$. Beban berat dari lemari arsip, alat dan mesin harus ditentukan tersendiri.

64 Penggunaan Program Komputer Pada Gedung Bertingkat Menggunakan Paket Program Sanspro V 4,7 (Singgih Subagyo) 


\subsection{Beban Angin.}

Menganggap adanya tekanan positif (pressure) dan tekanan negatif/isapan (suction) bekerja tegak lurus bidang yang ditinjau.

Adapun untuk mencari gaya geser dasar gempa untuk analisis static ekivalen dipakai rumus :

$$
V=C \times I \times K \times W t
$$

dengan $\quad V \quad$ = beban gempa horizontal

C = koefisien gempa

$I=$ faktor keutamaan g vedung $=1,0$

$K \quad=$ faktor jenis gedung $=1,0$

rumus :

$W t \quad=$ berat total gedung

$T=0,06 \times H^{3 / 4}$

$$
\begin{array}{cl}
\text { dengan }: \mathrm{T} & =\text { waktu getar alami } \\
\mathrm{H} & =\text { tinggi gedung }
\end{array}
$$

Besar geser gempa akibat gempa didistribusikan sepanjang tinggi struktur, menjadi gaya horizontal terpusat $F t$, yang brkerja pada masing - masing lantai dengan rumus :

$$
\begin{aligned}
& F i=\frac{W i \times h i}{\sum(W \times h i)} V \\
& \text { dengan : } F i=\text { beban gempa horizontal pada lantai } \\
& W i=\text { berat lantai } \\
& h i=\text { tinggi lantai } \\
& V=\text { beban dasar akibat gempa }
\end{aligned}
$$

\section{PEMBAHASAN DAN HASIL PENELITIAN}

\subsection{Umum}

Perencanaan struktur bangunan gedung terhadap beban gempa di Indonesia sangat penting. Beberapa kejadian gempa yang telah terjadi pada kurun waktu 3 tahun terakhir menunjukkan bahwa wilayah Indonesia termasuk dalam kategori wilayah gempa dengan intensitas moderat hingga tinggi. Secara umum, perencanaan struktur bangunan gedung beton bertulang tahan gempa berdasarkan standar peraturan gempa Indonesia [SNI 1726, 2002] dan standar peraturan beton Indonesia [SNI 03- 2847, 2002] dapat dilakukan dengan Sistem Rangka Pemikul Momen Menengah (SRPMM) dan Sistem Rangka Pemikul Momen Khusus (SRPMK). Kedua konsep perencanaan ini akan menghasilkan jumlah luas tulangan nominal untuk desain yang berbeda.

\subsection{Sistem Rangka Pemikul Momen}

Sesuai dengan peraturan beton Indonesia [SNI 03-2847, 2002] mengenai perencanaan struktur tahan gempa, untuk struktur bangunan dengan sistem struktur balok-kolom, terdapat ketentuan-ketentuan yang harus dipenuhi dalam detailing.

\subsection{Pendimensian dan Analisis Beban yang Bekerja}

Gedung direncanakan untuk suatu bangunan kantor bertingkat 6 yang berada di zona 2 peta wilayah gempa Indonesia dengan kondisi tanah di bawah bangunan adalah tanah lunak direncanakan dengan daktalitas penuh. Gambar denah dan dimensi elemen struktur dapat dilihat pada gambar 4.1 sampai gambar 4.3. Mutu beton yang digunakan (fc') 30 Mpa dan mutu baja yang digunakan (fy) 320 Mpa. Denah sketsa pembebanan dianggap telah memenuhi syarat tata letak struktur yang disyaratkan. 


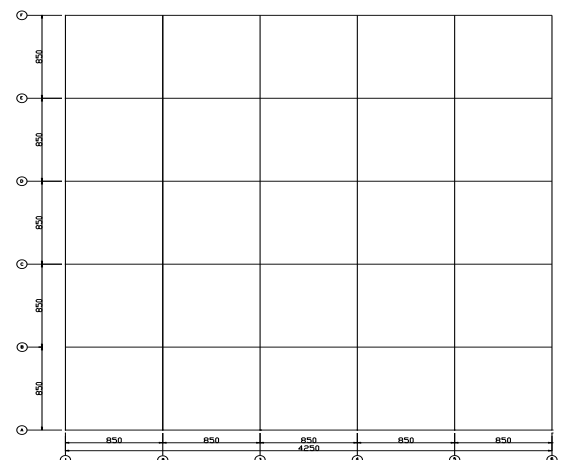

Gambar 4.1 denah lantai 1-6

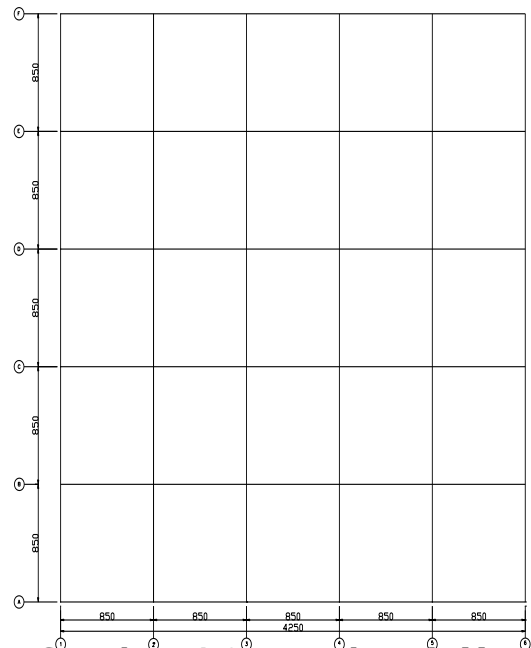

Gambar 4.2 portal arah X

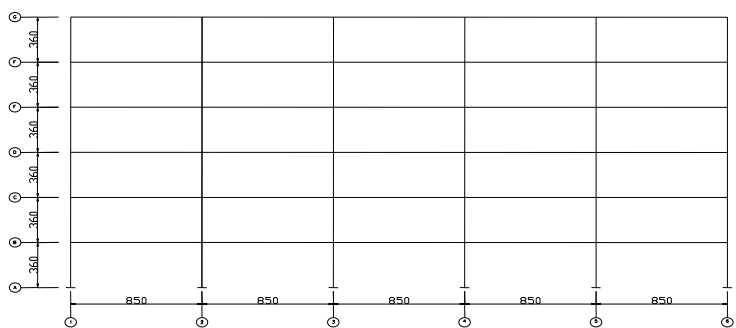

Gambar 4.3 portal arah Y

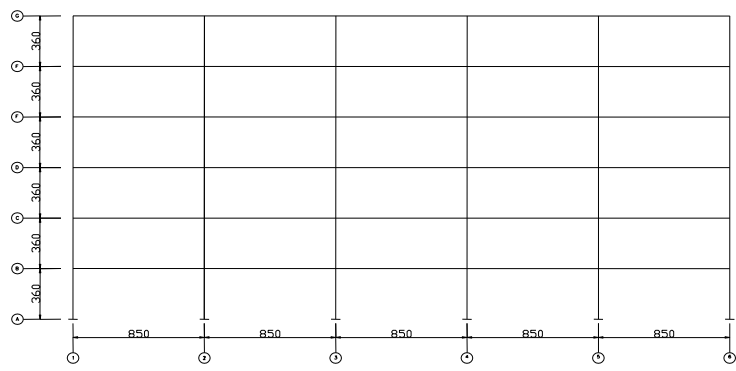

Gambar 4.3 portal arah $Y$

66 Penggunaan Program Komputer Pada Gedung Bertingkat Menggunakan Paket Program Sanspro V 4,7 (Singgih Subagyo) 


\subsection{Masuk ke program SANSPRO for windows}

Klik icon maka akan keluar tampilan SANSPRO: Kemudian klik ok , pilih buillding modeller.

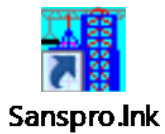

Langkah - langkah SANSPRO

Pembuatan model, Menetapkan parameter, Menetapkan building parameter, Menentukan data properties, Menentukan koordinat, Mendefinisikan storey data, Mendefinisikan kolom layout, Mendefinisikan beam lay option elset. Mendefinisikan jumlah dan jenis pelat lantai, Mendefinisikan floor slab region, Mendefinisikan beban balok, Mendefiniskan restrain, Mendefinisikan beban lateral ekivalen.

\subsection{Analisis}

1. Exporting data SANS

2. Anlisis struktur

3. Desain struktur

\subsection{Output}

1. Untuk berat tiap lantai tidak perlu dilakukan perhitungan secara manual, karena akan dihitung oleh sanspro sendiri.

2. Menampilkan beban gempa Pilih loading, Klik earthquake load

3. Menampilkan diagram bidang $M$ Klik kanan, Klik view moment diagram, Klik tanda panah ,Klik combo 1

4. Menampilkan reaksi perletakan Klik kanan lalu pilih view support reaction, Gunakan F12untuk mengecilkan font dan F11 untuk membesarkannya

5. Menampilkan hasil analisis

Hasil analisis berupa angka - angka yang menunjukkan hasil perhitungan oleh SANS, apabila terjadi kegagalan dan di nilai tidak aman akan ada laporan dalam hasil outputnya.

$>$ Klik menu analisis

$>$ View anaylisis output

6. Menampilkan hasil design balok dan kolom

Setelah dilakukan analisis SANS akan memberikan laporan mengenai jumlah tulangan dan jarak tulangan :

Klik kanan, View design result, Gunakan tombol panah untuk berpindah antar lantai

7. Potongan memanjang portal

Klik kanan view section $x-x$ or $y-y$, Aktifkan front klik select range, Jarring portal, Klik view

8. Rencana anggaran biaya

\section{UNIT COST :}

Unit cost of Concrete $=334425.0 / \mathrm{m} 3$

Unit cost of Steel Rebar $=3452.0 / \mathrm{kg}$

Unit cost of Slab Formwork $=53950.0 / \mathrm{m} 2$

Unit cost of Beam Formwork $=\quad 67850.0 / \mathrm{m} 2$

Unit cost of Column Formwork $=\quad 49170.0 / \mathrm{m} 2$

Unit cost of Wall Formwork $=49170.0 / \mathrm{m} 2$ 


$\begin{array}{llc}\text { Unit cost of Steel Profile } & = & 5250.0 / \mathrm{kg} \\ \text { Unit cost of Steel Angle } & = & 6000.0 / \mathrm{kg} \\ \text { Total : } & & \\ \text { Total Building Cost } & & 2,838,839,204.6 \\ \text { Total Floor Area } & = & 10476.3 \mathrm{~m} 2 \\ \text { Total CIP Slab Area } & = & 10476.3 \mathrm{~m} 2 \\ \text { Total Concrete Volume } & = & 1828.0 \mathrm{~m} 3 \\ \text { Total Rebar Weight } & = & 382297.7 \mathrm{~kg} \\ \text { Total Formwork Area } & = & 16039.7 \mathrm{~m} 2 \\ \text { Average Concrete Volume } & = & 0.1745 \mathrm{~m} 3 / \mathrm{m} 2 \\ \text { Average Rebar Weight } & = & 36.49 \mathrm{~kg} / \mathrm{m} 2 \\ \text { Average Overall Cost } & = & 270,978.6 / \mathrm{m} 2\end{array}$

\section{KESIMPULAN DAN SARAN}

Dari hasil analisis yang telah dilakukan dapat ditarik beberapa kesimpulan sebagai berikut:

1 Struktur yang direncanakan cukup kuat, sehingga masih dapat dilakukan evaluasi terhadap struktur agar lebih evisien dengan menggunakan diameter tulangan yang lebih besar dengan jumlah yang lebih sedikit.

2 Penggunaan SANSPRO dapat lebih menghemat waktu perencanaan, karena dalam analisis bisa dikerjakan tiga pekerjaan sekaligus yaitu pendesainan, penggambaran, dan perhitungan anggaran biaya.

3 Perlu dilakukan perbandingan dengan program yang lain semisal SAP 2000, ETAB dan lain-lain, manakah lebih efisien sehingga lebih menghemat biaya.

4 Perlu ketelitian dalam memasukkan input data karena penggunaan SANSPRO dengan banyak kesalahan akan mengakibatkan tidak berjalannya SANSPRO dan menyebabkan error.

5 Pada penelitian ini penulis juga menyadari masih banyak kesalahan, sehingga kalau ada yang meneruskan diharapkan lebih teliti.

\section{DAFTAR PUSTAKA}

G.Nawy Edward,. (1998) Beton Bertulang Suatu Pendekatan Dasar. Bandung: Refika Aditama

Kusuma Gideon, Andriono Takim (1993). Desain Struktut Rangka beton Bertulang di Daerah Rawan Gempa Berdasarkan SKSNI T-15-1991-03. Jakarta : Erlangga

Kusuma Gideon, W.C.Vis (1993). Dasar-dasar Perencanaan beton bertulang. Jakarta : Erlangga

Mahmud cholid, ---------, Dktat Kuliah Analis Gempa dan Dinamika struktur, Fakultas Teknik UCY, yogyakarta .

Mulyono Tri Ir, MT. (2004). Teknologi Beton. Yogyakarta : Andi offset

Pranata Yosafat Aji,------ Evaluasi Kinerja Gedung Beton Bertulang Bandung : Universitas Kristen Maranatha

Pramono Handi, Hendriana Ino. ( 2005 ). Desain Rangka dan Pondasi Beton dengan SANSpro 4.7. Jakarta : Maxicom.

Rangkuman PPIUG 1983 - Suyono Nt, 2007 SK SNI T-15-1991-03. Tata Cara

Perhitungan Struktur Beton Untuk Banggunan Gedung. Bandung : Yayasan $\angle P M B$. .

SNI 03-1726-2002. Tata Cara Perencanaan Ketahan Gempa Untuk Rumah dan Gedung. 